\title{
Innovations in civil engineering education at the interdisciplinary and production basis
}

\author{
Elena Shlyakhova, Irina Serebryanaya, Inna Egorochkina*, Andrey Matrosov, A.V. \\ Serdyukova
}

Don State Technical University, 344002, Rostov-on-Don, Russia

\begin{abstract}
Article is devoted to the problem of modernization of engineering education in modern economic conditions. This is necessary to provide qualified personnel for the construction industry. The authors considered innovative approaches to the organization of the educational process. They are based on interdisciplinary links of training of engineering and construction contingent in technical universities. And also on the introduction of digitalization in the teaching of disciplines of a natural science profile. We discussed the combination of traditional forms of training with production activities at existing enterprises of the industry. The work justified the relevance of modernization of engineering education, analysed factors that justify its need and ways to achieve the objectives. Studies have been carried out to assess the effectiveness of combining educational processes at the university with production activities at existing enterprises in Rostov-on-Don. To combine training and production processes in the training of qualified civil engineering personnel the structural division of the enterprise was allocated - the construction laboratory. The laboratory fully meets the tasks set by functional characteristics. Special working conditions of factory laboratories at small and medium-sized enterprises were noted. This is due to the difficult modern economic conditions. The main requirements for the personnel composition of factory laboratories of the new formation have been determined. These include depth and versatility of knowledge, non-standard thinking, flexibility in decision-making, interchangeability, readiness to improve knowledge and professional skills. The practical results of the experience of four years of combining innovative modernization of the training process of civil engineering personnel with production activities are presented. At the existing enterprises of the construction industry in Rostov-on-Don. The results confirm the high effectiveness of the proposed events.
\end{abstract}

\section{Introduction. Relevance of the problem}

The purpose of this work was the innovative modernization of civil engineering education in relation to the modern conditions of construction production.

\footnotetext{
*Corresponding author: arin77@bk.ru
} 
The relevance of the issue of modernization of the educational process is related to the following circumstances. Firstly, in the country there is an increasing shortage of qualified civil engineering personnel meeting modern requirements. Secondly, the technical universities that train these personnel should work in the new conditions of a multi-layered economy. Constantly look for optimal relationships between depth, breadth and attractiveness of engineering training.

In previous years, it was necessary and enough to work only according to established state educational standards. In modern conditions, this is no longer enough.

Knowledge, skills and skills, which are presented in educational programs of civil engineering disciplines are subject to mandatory assimilation and control. Now they need to be supplemented with new aspects of the educational process. Such aspects should include all events that will ensure the formation and development of modern engineering competence. They cannot be obtained by simply summing up a set of knowledge, skills and skills. Researchers note [1-4] that theoretical knowledge and practical methods of civil engineering activities need to be combined into one whole. There should be certain key values as system factors. The basis of the educational process in this approach will be not only educational disciplines, but also methods of engineering thinking and practical activities.

Successful engineering requires a high level of training, as well as the sociopsychological and spiritual and moral culture of a specialist.

That was why civil engineering should become innovative.

Innovative education - a process of purposeful formation of a set of knowledge, skills and skills in combination with a methodological culture. It is also a comprehensive training of specialists in the field of innovation engineering activities as a result of the use of appropriate methods and training technology [5-8].

Modernization of modern civil engineering education is connected with the need to change the following components of the educational process, that is, training in natural science, vocational and humanitarian disciplines.

It should be noted that training in the educational disciplines of the natural science profile (physics, chemistry, mathematics and others) is currently carried out in the country within the framework of well-developed scientific and educational schools. Innovative changes in the level of training in this area make sense to look from the point of view of digitalization of the educational process and knowledge control.

The problem of improving the quality of civil engineering personnel is quite different in the field of vocational, technical and humanitarian disciplines.

Training in humanitarian disciplines in traditional models of domestic higher engineering and construction education is a rational approach. The main idea of engineering is to meet the ever-growing needs of the modern society of mass production and consumption. Civil engineer should consider activity as a rational transformation of natural resources for the benefit of public material consumption. Rationality criteria take precedence over all others.

A post-industrial society with an evolutionary model of development is characterized by the predominance of an information intellectual resource over material and real categories. Under these conditions, information and knowledge, communication environment, new intelligent and digital technologies become at this stage the most important resource of social development. The role of humanitarian disciplines in the training of a new type of civil engineering specialists in these conditions is greatly increased.

In modern conditions, a civil engineer should be able to predict the economic, environmental and social consequences of both professional activities and the ideas and inventions offered to him. He must possess modern methods and technologies to implement 
new ideas and business projects. Must be able to work in a team and assume the role of leader.

Therefore, the problem of modernizing the educational process becomes especially urgent. It is necessary that students, starting from the initial stages of study, can practically form links between future professional areas of activity and humanitarian knowledge acquired at the university.

Such cross-disciplinary approach to educational process will promote formation at students of complete idea of the concrete field of the future professional activity $[9,10]$. It can be considered that the development and further improvement of innovative models of civil engineering education will help to move from the traditional presentation of the educational process to the creation of interdisciplinary programs. Such programs will be aimed at solving issues of construction quality management. The implementation of such programs should provide for students the possibility of rationally combining university training processes with directly productive activities at the current enterprise according to the profile of their chosen profession $[11,12]$.

\section{Research methods}

The method of measuring the maturity of production processes developed at Carnegie Mellon University was used to modernize the training process for civil engineering personnel. This method allows you to rank the level of maturity of the analyzed enterprises.

According to the model (Capability Maturity Model Integrated (CMMI)), the evaluation of process management and product quality management is considered at five levels [13]:

- first (initial) when processes have not yet been defined;

- second - some processes defined;

- third - processes are mainly defined;

- fourth - all processes are defined and monitored;

- fifth - processes are defined, systematized, methods and standards are constantly improved and updated.

Maturity level - a certain stage or stage in the development of the enterprise. The process of transition from a lower to a higher level allows the company to increase its competitiveness in modern economic conditions, which requires appropriate training of qualified engineering and construction personnel.

\section{Experimental results}

The experiment on innovations in civil engineering education was carried out at two enterprises in Rostov-on-Don - the Limited Liability Company (LLC) «Concrete-Don» and LLC «TD KSM 10».

An analysis of the actual state of production technology in these enterprises was carried out from the point of view of product quality management. Studies have shown that in terms of maturity, enterprises belong to the first (initial) level.

To implement a process approach that can be combined with a training process, the enterprise has allocated a structural unit - a construction laboratory.

The laboratory is an important department in any enterprise. The laboratory assesses the quality of raw materials and semi-finished products, monitors the main operational processes, accepts finished products according to all standardized quality indicators.

In modern conditions, in enterprises of any level, the laboratory should play a key role not only to establish parameters of conformity of quality of raw materials and finished products. It should act as an engine and implementer of innovative ideas, technologies, 
materials. And for this it is necessary to provide the laboratory with qualified personnel. Factory laboratories at construction enterprises can make a significant contribution to improving productivity and safety of work, ensuring a transition to a higher level of maturity of production, and increasing the competitiveness of products.

Tightening market competition, increasing production volumes, open borders for the import of goods were increasingly shifting the focus towards the development and introduction of methods and techniques for improving product quality. The options for quality improvement are modernization of equipment and technical re-equipment of production, training and training of personnel, introduction of new methods of enterprise management, quality control at all stages of production.

One of the most important elements of the quality management system in modern companies is business process management. These processes should be constantly improved and developed [13].

The above principles were the basis for the development and implementation of the elements of the master's program 27.04.02 "Quality Management" focus (profile) "Engineering and digitalization of business processes" and 08.04.01 "Construction" focus (profile) "Production of building materials, products and structures" in relation to the production conditions of the limited liability company «TD KSM 10» and LLC «Concrete Don», Rostov-on-Don.

The issues of quality improvement are closely related to the introduction of automation and digitalization at the enterprises of the construction industry, which are most in need of innovation today. These events should help introduce new types of raw materials into the production of concrete and ferroconcrete products and structures. And apply modern production schemes, conduct research of a scientific nature and work to improve the quality of production.

Special working conditions of factory laboratories at small and medium-sized enterprises should be noted. These include the lack of the possibility of increasing the staff of the laboratory. This is due to the difficult modern economic conditions. The staff of such laboratories should have universal knowledge. Must be interchangeable. Be able to work in a team and have non-standard thinking. Exercise flexibility in decision-making and strive to continuously improve and deepen scientific knowledge. New technologies and modern equipment, a growing number of innovative raw materials, the work of the enterprise in the conditions of digitalization requires training for laboratories of personnel of a new formation.

The use of interdisciplinary linkages for this purpose in the training of civil engineering personnel at technical universities will provide specialists to work in modern socioeconomic conditions with the required knowledge and skills in the field of innovation engineering activities.

In the laboratories of the enterprises of LLC «TD KSM 10» and LLC «Concrete Don» for more than four years a business project in which students participate has been implemented. Students of the Don State Technical University under the guidance of an assistant professor of the department «Technological Engineering and Expertise in the Construction Industry» doctor Shlyakhova E.A. During this time, seven students were involved in work in factory laboratories. Students successfully combined production activities and the educational process and put into practice an interdisciplinary approach to the process of forming civil engineering education. Students at the enterprise were registered as laboratory engineers (master) or laboratory assistants (bachelor). This allowed them to gain not only work experience, but also official work experience. As shown by the conducted research, combination of work and educational activities allows the application of theoretical knowledge in practice. This knowledge was obtained in the educational process in scientific, vocational and humanitarian disciplines. 
All students who took part in the project had an excellent attestation based on the results of their studies. To date, five people have already received master's degrees in the program 08.04.01. Three people received honors.

In the course of work, the students participating in the project gained practical skills in assessing the quality of raw materials and finished products using standard standardized methods. And also took part in research work to improve the quality of products and the development of new compositions of concrete mixtures. The results of scientific activity of students obtained in the conditions of the factory laboratory were published in open print. And they also found practical way out in the form of sections of graduate qualification work at the university. In 2019, master A.A. Zarovny, a participant in the project, received a diploma from the Association of Construction Universities of the Russian Federation in the All-Russian competition of graduate qualification works. In the nomination "Master's Research Institute in the Field of Construction Materials Science" in the direction of 08.04.01 "Construction," he received 1st place and was nominated for a medal in the RAASN competition.

During the period of implementation of the project on innovative formation of the strategy of civil engineering education through interdisciplinary connections in the educational process, students-participants published more than 30 articles of various levels - RISC, HAC, and Scopus [14, 15]. They took part in international conferences, scientific seminars with presentations of the results of scientific and practical activities. With their participation, two patents of the Russian Federation were received [16, 17]. The results of the study of the effectiveness of the project under consideration are presented in Table.

Table 1. Efficiency indicators of the method of preparation of civil engineering personnel

\begin{tabular}{|l|c|c|}
\hline \multirow{2}{*}{$\begin{array}{c}\text { Indicators to be compared for } \\
\text { analyzed period of 2017-2020 years }\end{array}$} & Form of education \\
\cline { 2 - 3 } & traditional & $\begin{array}{c}\text { participants } \\
\text { project }\end{array}$ \\
\hline Academic performance & $87 \%$ & $100 \%$ \\
\hline Performance on "good" and "excellent" & $61 \%$ & $100 \%$ \\
\hline Obtained diplomas with honors degree & $20 \%$ & $60 \%$ \\
\hline $\begin{array}{l}\text { Winning prizes at the All-Russian VKR } \\
\text { competition }\end{array}$ & 0 & 1 \\
\hline $\begin{array}{l}\text { Obtained patents of the Russian Federation } \\
\text { in the specialty profile }\end{array}$ & 0 & 2 \\
\hline $\begin{array}{l}\text { Have priority in employment on the } \\
\text { presence of seniority after graduation }\end{array}$ & $27 \%$ & $100 \%$ \\
\hline Work in the specialty & $76 \%$ & $100 \%$ \\
\hline $\begin{array}{l}\text { He holds main positions (head of laboratory, } \\
\text { head of production, main technologist) }\end{array}$ & $22 \%$ & $100 \%$ \\
\hline
\end{tabular}

\section{Conclusion}

The experience of combining the innovative modernization of the training process of civil engineering personnel with production activities at existing enterprises of the construction industry confirmed the high effectiveness of such a strategy.

The further direction of research in the field of innovation in civil engineering education should include the development of the training of highly qualified personnel. This is especially important for students who combine theoretical training with production activities according to individual plans. 
The work of scientific leaders of innovative training of students according to individual plans should be included in the teaching workload of teachers.

\section{References}

1. Yu.M. Kazakov, N.Y. Bashkirtseva, M.V. Zhuravleva, G.O. Yezhkova, A.S. Sirotkin, A.O. Ebel, Higher education in Russia 12 (29), 105-118 (2020)

2. P.M. Yesterday, N.V. Gafurova, M.V. Rumyantsev, O.A. Osipenko, Higher education in Russia 8-9 (204), 15-21 (2016)

3. V.V. Karmanov, S.V. Karmanova, I.L. Ge-Rasimchuk, Higher education in Russia 4, 56-61 (2015)

4. S.G. Vinogradova, A.T. Smirnova, Higher education in Russia 11, 129-140 (2020)

5. N. Chigirinskaya, Engineering education strategy: interdisciplinary approach, Higher education in Russia 2, 36-40 (2007)

6. R.G. Strongin, E.V. Chuprunov, Higher education in Russia 12, 5-14 (2014)

7. A.E. Vorobyov, B.T. Torobekov, Modernization of Russian higher education in response to the challenges of our time (KnoRusCompany, Moscow, 2014)

8. E.I. Makarenko, Man, Socium, Society 2, 8-17 (2020)

9. S.Yu. Rzheutskaya, M.V. Harina, Open education 2 (21), 21-28 (2017)

10. O.F. Piralova, P.N. Blinov, F.F. Vedyakin, News of the Volgograd State Pedagogical University 4 (89), $71-75$ (2014)

11. S.N. Petrova, N.V. Korzhavina, T.V. Gurskaya, Bulletin of Lenin-Grad State University named after A.S. Pushkin 2, 173-189 (2020).

12. O.I. Pakhomova, Education and self-development 2 (24), 189-194 (2011)

13. V.V. Repin, Mann, Ivanov and Ferber, Moscow (2013)

14. E.A. Shlyakhova, I.O. Egorochkina, I.A. Serebryanya, S.M. Madatyan, A.A. Zaprutsky, Improving the mixtures preparation technology for in-situ concrete, IOP Conference series: Materials science and engineering Construction and Architecture: Theory and Practice of Innovative Development" (CATPID-2020). Institute of Physics Publishing 032041 (2020). DOI: 10.1088/1757-899X/913/3/032041

15. A. Cherpakov, I. Egorochkina, E. Shlyakhova, A. Kharitonov, A. Zarovny, S. Dobrohodskaya, MATEC Web of Conferences (2017) 04009. DOI: 10.1051/matecconf/201710604009

16. E.A. Shlyakhova, M.A. Shlyakhov, Concrete mixture, Patent for invention RU 2606147 C1 (2017), ID: 38257116

17. E.A. Shlyakhova, A.A. Zaprutsky, M.A. Odinets, Yu.A. Gurskaya, Method of concrete mix preparation for high-strength concrete, Patent for invention RU 2739006C1 (2020). 